\title{
Superconductivity deal opens path to peace
}

Boston. The first commercial agreement stemming from an ambitious effort by the United States to curb the spread of nuclear weapons and related technology in countries of the newly-independent states (NIS) of the former Soviet Union was signed last week by Sandia National Laboratories in Albuquerque, New Mexico, ELTECH, a research institute in St Petersburg, Russia, and Superconducting Core Technologies (SCT) of Golden, Colorado.

The idea is the brainchild of Senator Pete Domenici (Republican, New Mexico), who sponsored legislation creating the Industrial Partnering Program (IPP). This programme, which is administered by the Department of Energy (DoE) and started last June, supports research collaboration between DoE laboratories and their NIS counterparts.

The aim is to engage NIS weapons scientists and engineers in developing civilian, commercially-orientated technology, in order to reduce their inclination either to continue to work on nuclear weapons domestically or to take their skills to another aspiring nuclear power. It is also hoped that the joint ventures will result in marketable products with the help of the US Industrial Coalition (USIC), an alliance of 76 compa- nies formed under IPP.

"Until now, no one had thought of involving US industry directly in the non-proliferation process," says John Hnatio, the programme manager for IPP at DoE. "I'm convinced that this is the best national security investment this country could make." Michael Deegan, president of USIC, says the venture is "peace on the cheap".

More than 200 research projects have so far been initiated in fields as diverse as materials processing, renewable energy technologies, environmental cleanup and waste management. US laboratories nurture these small-scale research and development projects through an incubation stage. explains Dennis Croessmann, programme manager at Sandia Laboratories. Officials then select those that appear to be the most commercially viable and try to interest outside companies.

The two-year contract with ELTECH and SCT involves developing tunable microwave filters made with high-temperature, superconducting thin films and ferroelectric materials to improve communications on cellular phones. "SCT had already been talking with us and the Russians before IPP was even in place," explains Duane Dimos, who heads the Sandia effort. The relationship, he says, combines ELTECH's strength in microwave components with Sandia's expertise in ferroelectrics and SCT's marketing knowledge.

"This first agreement was probably the toughest, given the differences between the US and NIS systems," says Croessmann. "Now that we've been through it, the next ones should be a lot easier." Twenty more commercialization agreements are close to being signed, with 10 more pending.

Participants are enthusiastic about the flood of new ideas. "There's been a wall between these countries for decades," Croessmann says. "Now we have the chance to tap into a motherlode of technology across a broad range of research areas."

William Collins, vice president of USIC, accepts that there is a 'bonanza' waiting to be tapped - but warns that it may be difficult to reach. "We help companies learn about new opportunities and we share in the investment cost"

In courses taught at 13 universities, US scientists and business people learn about various aspects of doing business with the NIS. At the same time, NIS scientists learn how to commercialize and market their technology.

Steve Nadis

\section{European nations to collaborate on flood research}

Munich. Four European countries have agreed to work together, in collaboration with the European Commission, on developing research programmes in response to the recent Rhine floods.

The proposed programmes will focus on modelling the basins of the two rivers whose flooding poses the biggest threat to northern Europe, the Rhine and the Meuse. The international collaboration follows an initiative by the Dutch minister of science, who is particularly concerned at the way in which the flooded river threatened to burst his country's dikes.

The past century has seen a significant change in response of the Rhine to heavy rains. Hydrological records show that, 100 years ago, increases in river flow after heavy rains were spread over eight to ten days. Today the extra flow is concentrated in little more than half that time.

One reason has been the straightening of the river to make it more navigable, and its separation by dikes from the flood plains that previously buffered peak flows. Climate change may also be a factor because of its impact on rainfall.

A few days after the floods at the end of January, the environment ministers of France, Germany, Belgium, Luxembourg and the Netherlands issued a joint statement describing as "unacceptable" the risks to

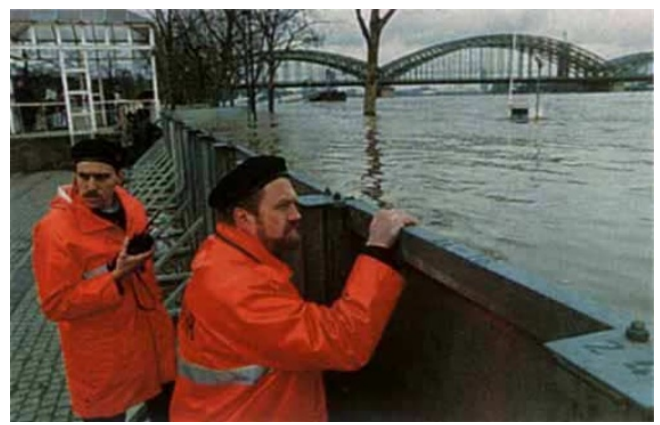

Up to the brim: Food barriers in Cologne

"life, property and the environment" of frequent severe flooding. They called for broad international measures on the implications of land use and water management.

In a separate move, the Dutch research minister, Jo Ritzen, hosted a meeting in Maastricht on 16 February, with representatives from Germany, Belgium and the commission, to discuss international collaboration in research on flooding.

The commission agreed to support a workshop in April in Brussels to develop research proposals for modelling the Rhine and Meuse, and for improving understanding of dyke construction and dike failure.

The commission is already sponsoring a series of expert meetings to prepare for the workshop, and wants to bring more com- plete models of the rivers into operation within two years, to give the Low Countries a longer period of flood warning. The eventual objective of the research, says a commission spokesman, is to provide government authorities in the countries that cooperate through the International Rhine Commission with information to help to deal with future floods.

Two Dutch institutes brought proposals to the meeting that will serve as a basis for developing collaborative programmes with institutes in the other states. The Delft Hydraulics Laboratory wants to collect data from the spans of river that have already been modelled, and fill in the gaps. The Delft Geotechnics Laboratory is planning to examine the response of dikes to severe loads; it is particularly interested in the situation caused by two floods in close succession, where the second must be contained by dikes already fully saturated.

"There is no simulation model of the whole of the Rhine basin and this is what we need if we are to get more advanced predictions, maybe one or two days ahead", says Peter Tindemans of the Dutch ministry of education and science. "Furthermore, we don't have enough information about the conditions of all the dikes because many are so old."

Alison Abbott 